\title{
Editorial
}

\section{The crucial link between academic conferences and journals}

Academic researchers attend conferences in order to discuss their ideas and research, and to obtain valuable feedback. Conferences are the places where research communities are built and maintained through presentations, discussion, and informal social interaction. Strong vibrant conferences are crucial to the quality and longevity of a research field. For this reason, we are delighted that there are a number of active eGovernment conferences research research that help authors to develop their research papers.

As Editors-in-chief of Information Polity we are keen to establish positive relationships with key conferences in our field since our journal is another component of the research ecosystem of e-government scholars. Connecting conferences and journals also helps to make the most interesting and thoughtful work available to the broader research community. In that sense, the eGovernment research ecosystem is being strengthened by connections between conferences and journals.

Information Polity has a longstanding relationship with two main conferences in our field: (1) the Annual International Conference on Digital Government Research (dg.o) organized by the Digital Government Society, and (2) the Annual Conference of the European Group for Public Administration (EGPA), with Permanent Study Group 1 focussing on eGovernment and Permanent Study Group 15 on Public Administration, Technology and Innovation. Over the years, we have published a number of thematic special issues, sections with linked papers and individual papers from these conferences. We feel that the connection between our journal and these conferences provides mutual benefits and contributes to a strong research community of eGovernment scholars.

This issue of Information Polity presents a set of papers from the 19th Annual International Conference on Digital Government Research (dg.o) organized by the Digital Government Society in 2018 in Delft. Anneke Zuiderwijk-van Eijk and Chris Hinnant have kindly agreed to be the editors of this section. The editors of the special introduce this section with a review of open data research. The various papers in this section discuss issues such as open data portals and the right to public sector information. This coherent set helps to provide a strong academic understanding of the state of knowledge regarding open data research.

Our connection with conferences certainly does not mean that we are not open to other articles. We will generally not limit issues of Information Polity to papers from a conference and will always provide room for other interesting contributions. This is also the reason why we talk about a section and not about a special issue. In fact, this issue of Information Polity presents highly interesting papers on smart cities and mobile participation. A connection to conferences is productive, but we will certainly not limit this journal to these connections.

Also, whilst we have established excellent connections with the dg.o and EGPA conferencesthis does not mean we are not open to collaborations with other conferences. As we have indicated, we feel that strong relations between journals and conferences are key to the vitality of a research community. We 
are open to new collaborations, if the nature of the conference and the quality of the contributions align with the objectives of Information Polity. Let's work together to strengthen the various linkages in this broad research community further to ensure strong connections between discussions at conferences and papers in journals.

Albert Meijer William Webster 